\title{
REVIEW
}

\section{Spirometry and peak expiratory flow in the primary care management of COPD}

\author{
Patrick White ${ }^{a, b}$
}

\author{
a Department of General Practice \& Primary Care, Guy's, King's \& St. Thomas' School of Medicine, \\ King's College London, 5 Lambeth Walk, London SE11 6SP, London, UK \\ ${ }^{\mathrm{b}}$ Crowndale Medical Centre, London SE19 3NY, London, UK
}

\author{
KEYWORDS \\ Spirometry; \\ COPD; \\ Primary care; \\ Chronic obstructive \\ pulmonary disease
}

\begin{abstract}
Summary Spirometry is essential for the diagnosis of chronic obstructive pulmonary disease (COPD). In patients with COPD the decline in lung function is usually so slow that spirometry is unlikely to provide significantly new information more than every 1-2 years. However, it is useful to have an objective measure of lung function in the assessment of acute exacerbations of COPD and in the assessment of treatments.

Peak expiratory flow (PEE) has been dismissed by national and international guidelines as an inappropriate test for the assessment of the impact of COPD, but with poor evidence in support of this position. This seems short-sighted since PEF is a reliable and reproducible test and could contribute to the management of COPD in the short term and in-support of spirometry. As a result of infection or in response to treatment there may be changes in airway calibre in COPD which could be captured in the consultation by PEF. In a primary care setting spirometry is too time consuming and complex to be provided in the context of normal acute consulting. Furthermore there is no evidence that spirometry provides more information than PEF in the day-to-day management of a patient already diagnosed with COPD using forced expiratory volume in the first second/forced vital capacity ( $\left.F E V_{1} / F V C\right)$.

Primary care teams should ensure that their patients have adequate access to high quality spirometry. This can be provided in primary care or in local centres or in hospitals depending on the interest, motivation and resources of primary care teams. In support of spirometry general practitioners (GPs) should then consider using PEF in the day-to-day management of COPD.
\end{abstract}

(c) 2003 General Practice Airways Group. Published by Elsevier Ltd. All rights reserved.

\section{Introduction}

International guidelines for the management of chronic obstructive pulmonary disease (COPD) have declared that spirometry is the only acceptable objective measure of the impact of COPD both in the diagnosis and in the continuing management of the disease $[1,2]$. This has presented primary care

E-mail address: patrick.white@kcl.ac.uk (P. White). teams with a difficult choice. Should they invest in spirometry as a routine disease management tool in primary care? Or should primary care teams rely on hospital laboratory services for the diagnosis of COPD, and use history and examination alone for its day-to-day clinical assessment? Or is there another way in the primary care management of COPD? Many general practitioners (GPs) have opted for practice-based spirometry as the only credible approach to good clinical care of COPD. This option is supported by a growing literature on the use 
of spirometry in the primary care management of COPD [3]. Most recently the new contract for GPs in the UK has specifically named the annual measurement of forced expiratory volume in the first second $\left(\mathrm{FEV}_{1}\right)$ in COPD as a quality measure which will earn a financial reward [4]. In addition to the use of spirometry in the diagnosis of suspected COPD and in its day-to-day management, spirometry has recently been promoted as a screening tool for the early detection of COPD $[5,6]$. These proposed roles for spirometry in primary care COPD management are based on two assumptions. The first assumption is that peak expiratory flow (PEF) should have no role in the management of COPD. The second assumption is that spirometry is a suitable desktop tool for use in standard general practitioner consultations. Neither of these assumptions is well supported by evidence. In this paper the evidence for the unsuitability of PEF in the day-to-day management of COPD is questioned. The factors which limit the use of spirometry in routine primary care consultations are considered and a proposal is made for the integration of PEF and spirometry in the objective assessment of COPD outcome.

\section{Peak expiratory flow in COPD}

British Thoracic Society Guidelines, and dater the Global Initiative for Chronic obstructive Lung Disease (GOLD) have both based their rejection of peak expiratory flow as a useful clinical test in COPD on research which actually proposed the opposite, the superiority of PEF over forced expiratory volume in the first second $\left(\mathrm{FEV}_{1}\right)[1,2,7]$. Concerns about the limitations of PEF have been about the reliability and reproducibility of the test itself, and about the capacity of the test to give an adequate assessment of the loss of lung function in COPD. There is good evidence that PEF, measured with a hand-held peak flow meter, is both reliable and reproducible [8-12]. A recent report suggests that PEF may be more reproducible than $\mathrm{FEV}_{1}$ [12].

The status of PEF has been undermined by the persistent use of inaccurate reference equations for predicted normal values. In the UK, for example, the Association for Respiratory Technology and Physiology has continued to endorse the predicted values for PEF derived from the European Coal and Steel Community survey $[13,14]$. The equations from which their values are derived significantly underestimate predicted values in adults compared to the equations of Nunn and Gregg which are now preferred by the European Respiratory Society $[11,15]$. They have led to PEF being presented in report outputs from lung function laboratories as equal to or greater than the predicted values for age sex and height in patients in whom the $\mathrm{FEV}_{1}$ is less then predicted. They undermine clinicians' confidence in PEF as a measure. Although the problem of inaccuracies with predicted values is not unique to PEF and is also seen in $\mathrm{FEV}_{1}$, as Roca et al. have demonstrated, the observation is damaging to the perception of PEF because $\mathrm{FEV}_{1}$ is referred to as the gold standard [16].

A second but less obvious problem has been the inaccuracy of the scale of measurement used on European peak flow metres [17]. Miller et al. have shown that peak flow meters have characteristic error profiles which under-read peak flow at lower and higher flow rates and over-read flow in the middle range $[8,18]$. These errors are easily correctable mathematically and more accurate scales approved by the American Thoracic Society are provided for peak flow meters in North America [19]. The failure to correct the scates of peak flow meters in Europe reflects difficulty in agreeing a policy on standards for peak flow meters in the European Union.

The most important reason to doubt the usefulness of PEF compared to spirometry (and $\mathrm{FEV}_{1}$ in particular) in COPD lies in the difference in the information each provides. PEF is recorded in the first tenth of a second of forced expiration. FEV $_{1}$ continues to record forced expiration for a further $0.9 \mathrm{~s}$. As expiration progresses the volume of expired air falls as the flow rate falls. FEV 1 records what happens to expired air after peak flow is reached. It is in this component of forced expiration that the changes characteristic of COPD are observed. Instead of the steady proportional decline of expiratory flow which is seen in normal subjects after peak flow is reached (Fig. 1a), the flow rate collapses in patients with severe COPD (Fig. 1b). The sudden fall in expiratory flow is due to the structural damage caused by COPD. Loss of the parenchymal architecture of the lung through the chronic inflammatory processes of COPD removes the elastic support of the small airways. The rise in intra-thoracic pressure during expiration causes some small airways to collapse, trapping air in the alveoli and preventing its expiration, leading to a sudden drop in expiratory flow. This damage in COPD is permanent and progressive, and cannot be reversed by treatment. It is this pathological process which is measured by spirometry and which cannot be assessed by PEF. This is why $\mathrm{FEV}_{1} / \mathrm{FVC}$ is the diagnostic test of choice for COPD.

The decline in lung function in COPD is slowly progressive [2]. There is no point in assessing the decline in $\mathrm{FEV}_{1} / \mathrm{FEC}$ more than every $1-2$ years. In 


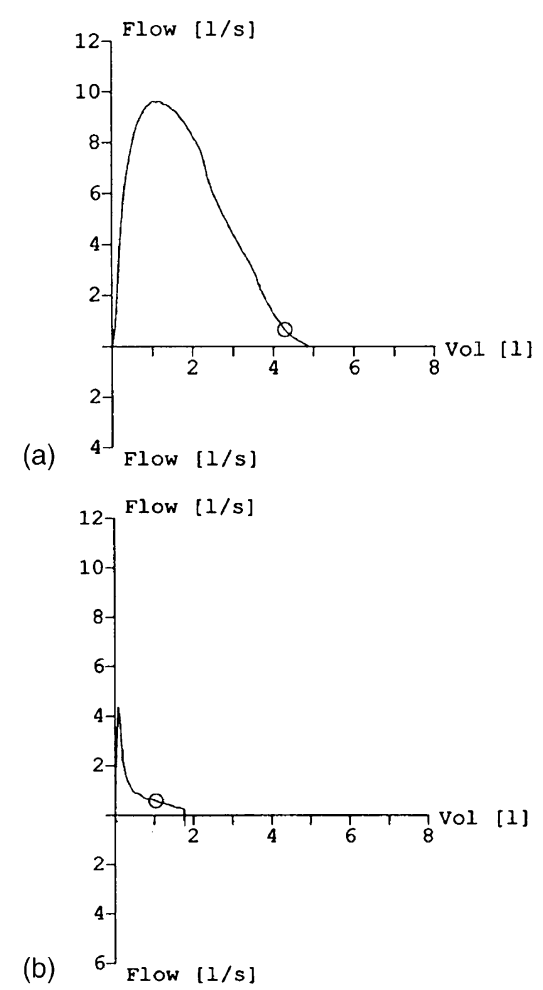

Figure 1 Flow volume loops from a person with normal lung function (a) and a person with advanced COPD (b).

the meantime important short term changes occur in airway calibre in response to acute exacerbations and in response to treatment [20-22] Acute exacerbations lead to narrowing of the bronchi and bronchioles with increasing mucous, inflammatory exudate, and muscle spasm. There are other elements of lung function which are increasingly recognised as important in COPD such as the inspiratory reserve capacity and relaxed vital capacity, but the immediate changes which result from infection or which improve with treatment of exacerbations are those of airway calibre [23] Although the pathological basis of the reversible elements of COPD is different to that of asthma, the effect is similar in that the key dynamic element is airway calibre. Why should PEF be less useful in measuring changes in airway calibre in COPD than it is in asthma? According to this reasoning PEF should be as useful in the short term evaluation of COPD as it is in asthma.

If there is no advantage in spirometry compared to PEF in measuring the short term changes in COPD should primary care teams not continue to use PEF in the day-to-day management of COPD? Since there is no dispute about the pre-eminence of spirometry in the diagnosis of COPD the challenge for primary care should be to consider how best to acquire high quality access to spirometry to add to existing provision of PEF.

\section{Access to spirometry in primary care}

Spirometry is relatively easy to perform with appropriate training and adequate facilities. It should be possible to provide high quality spirometry in primary care if staff are motivated and well supported. There are many reports of primary care teams integrating spirometry into their care of patients with respiratory disease which have demonstrated that it is feasible and acceptable [3,5]. The British Thoracic Society Guidelines for the management of COPD outlined three possible options for primary care teams: spirometry provided by the primary care team, a mobile visiting spirometry service, or open access to hospital laboratory spirometry [1]. To these may be added the option of primary care based recording of spirometry with a local respiratory specialist or general practitioner with a special interest providing reporting of the results electronically, "down the line". The advantages and disadvantages of these methods have been described in detail by Schermer et al. in this journal in 2000 [3].

However, spirometry is time consuming and cannot be performed easily in the course of a normal consultation. It is considerably more time consuming and complex than PEF recording $[13,19]$. Patients should be at rest for at least 5 min before the test. They require instruction in carrying out the test especially if they nave not done it previously. Experienced technicians allow at least 10 min per test. van Schayck's and Chavennes' report that it takes about 4 min to carry out spirometry in primary care seems overoptimistic, especially in patients with reduced lung capacity and limited exercise tolerance [5]. This is not a desktop test which can be easily administered without warning in the course of a GP's or practice nurse's consulting session.

When patients attend acutely with exacerbations of COPD spirometry has to be arranged at a later appointment unless the clinician has unexpectedly the time and opportunity there and then, or unless there is another colleague free to do the test. Realistically the choice facing the clinician is either to settle for PEF during the consultation and to arrange to have spirometry done later, or to continue the clinical assessment without any form of lung function measurement. PEF may add useful information about airway calibre at the time of presentation which can be re-measured at review on recovery or after treatment.

Despite enthusiasm and commitment spirometry may be done unacceptably badly in primary care [24]. The decision to provide spirometry in primary care must therefore be determined by the capacity 
and motivation of the primary care team to provide a reliable and high quality service to the patient.

\section{Conclusion}

Spirometry is essential for the diagnosis of COPD. In patients with COPD the decline in lung function is usually so slow that spirometry is unlikely to provide significantly new information more than every 1-2 years. In a primary care setting spirometry is too time consuming and complex to be provided in the context of normal acute consulting. Furthermore there is no evidence that in a patient already diagnosed with COPD spirometry provides more information than PEF in the day-to-day management of the condition. Primary care teams should therefore ensure firstly that their patients have adequate access to high quality spirometry. This can be provided in primary care or in local centres or in hospitals. In support of spirometry GPs should consider using PEF in the day-to-day management of COPD.

\section{References}

[1] BTS guidelines for the management of chronic obstructive pulmonary disease. The COPD Guidelines Group of the Standards of Care Committee of the BTS. Thorax 1997;52(Suppl 5):S1-28.

[2] Pauwels RA, Buist AS, Ma P, Jenkins CR, Hurd SS. Global strategy for the diagnosis, management, and prevention of chronic obstructive pulmonary disease: National Heart, Lung, and Blood Institute and World Health Organization Gtobal Initiative for Chronic Obstructive Lung Disease (GOLD): executive summary. Respir Care 2001;46(8):798825.

[3] Schermer TRJ, Folgering HTM, Buttema BJAM, Jacobs JE, van Schayck CP, van Weel C. The value of spirometry for primary care: asthma and COPD. Prim Care Respir J 2000;9(3):51-5.

[4] General Practitioners Committee, The NHS Confederation. New GMS Contract 2003. Investing in general practice. London: British Medical Association; 2003.

[5] van Schayck CP, Chavannes NH. Detection of asthma and chronic obstructive pulmonary disease in primary care. Eur Respir J Suppl 2003;39:16s-22s.

[6] van Schayck CP, Loozen JM, Wagena E, Akkermans RP, Wesseling GJ. Detecting patients at a high risk of developing chronic obstructive pulmonary disease in general practice: cross sectional case finding study. $\mathrm{Br}$ Med J 2002;324(7350):1370.

[7] Kelly CA, Gibson GJ. Relation between FEV and peak expiratory flow in patients with chronic airflow obstruction. Thorax 1988;43:335-6.
[8] Miller MR, Dickinson SA, Hitchings DJ. The accuracy of portable peak flow meters. Thorax 1992;47:904-9.

[9] Miller MR, Ouanjer PH. Peak flow meters: a problem of scale. Br Med J 1994;308(6928):548-9.

[10] Pedersen OF, Miller MR, van der Mark TW. Performance testing new peak flow meters. Eur Respir J 1998;12: 261-2.

[11] Quanjer PH, Lebowitz MD, Gregg I, Miller MR, Pedersen OF. Peak expiratory flow: conclusions and recommendations of a Working Party of the European Respiratory Society. Eur Respir J 1997;24(Suppl):2S-8S.

[12] White PT, Cajeat E, Fleming T, Gray B, Nolan D. The relationship between peak expiratory flow rate (PEFR) and forced expiratory volume in the first second $\left(\mathrm{FEV}_{1}\right)$. Implications for the assessment of COPD (chronic obstructive pulmonary disease) in primary care. Eur Respir J 2002;20(Suppl 38):397s.

[13] Bush A, Cramer D. Guidelines for the measurement of respiratory-function. Respir Med 1994;88(10):798.

[14] Quanjer PH, Tammeling GJ, Cotes JE, Pedersen OF, Peslin R, Yernault JC. Lung-volumes and forced ventilatory flows-Report Working Party Standardization of Lung-Function Tests European-Community for Steel and Coal-Official Statement of the European Respiratory Society. Eur Respir J 1993;6:5-40.

[15] Nunn AJ, Gregg I. New regression equations for predicting peak expiratory flow in adults. Br Med J 1989;298:106870.

[16] Roca J, Burgos F, Sunyer J, Saez M, Chinn S, Anto JM, et al. References values for forced spirometry. Eur Respir J 1998;11(6): 1354-62.

[17] Miller MR, Quanjer PH. Peak flow meters-a problem of scale. Br Med J 1994;308(6928):548-9.

[18] Pedersen OF, Miller MR. The Peak Flow Working Group: test of portable peak flow meters by explosive decompression. Eur Respir J 1997;24(Suppl):23S-5S.

[19] Committee on Proficiency Standards for Clinical Pulmonary Function Laboratories, American Thoracic Society. Standardization of Spirometry, Am. J. Respir. Crit. Care Med. 1995; 152:1107-36.

[20] Ram FS, Sestini P. Regular inhaled short acting beta2 agonists for the management of stable chronic obstructive pulmonary disease: cochrane systematic review and meta-analysis. Thorax 2003;58(7):580-4.

[21] Irwin RS, Madison JM. Systemic corticosteroids for acute exacerbations of chronic obstructive pulmonary disease. $\mathrm{N}$ Engl J Med 2003;348(26):2679-81.

[22] Donohue JF, van Noord JA, Bateman ED, Langley SJ, Lee A, Witek Jr TJ, et al. A 6-month, placebo-controlled study comparing lung function and health status changes in COPD patients treated with tiotropium or salmeterol. Chest 2002;122(1):47-55.

[23] O’Donnell DE, Lam M, Webb KA. Spirometric correlates of improvement in exercise performance after anticholinergic therapy in chronic obstructive pulmonary disease. Am J Respir Crit Care Med 1999;160(2):542-9.

[24] Eaton T, Withy S, Garrett JE, Mercer J, Whitlock RM, Rea $\mathrm{HH}$. Spirometry in primary care practice: the importance of quality assurance and the impact of spirometry workshops. Chest 1999;116(2):416-23.

Available online at www.sciencedirect.com

science $(\mathcal{b}$ irect. 